\title{
Sistem Monitoring Jentik Nyamuk Di Desa Muktiharjo \\ Berbasis Mobile
}

\author{
Arief Puji Eka Prasetya ${ }^{1)}$, Oky Dwi Nurhayati ${ }^{2)}$, Kurniawan Teguh Martono ${ }^{2)}$ \\ Program Studi Sistem Komputer, Fakultas Teknik, Universitas Diponegoro \\ Jalan Prof. Sudharto, Tembalang, Semarang, Indonesia
}

\begin{abstract}
High dengue fever cases strongly influenced by the behavior of the public them self. Almost most of the territory in urban and rural areas can be considered as potentially endemic. In the development of the Center of Desease Control give serious action against the locations of the potential for development of the Aedes Aegypti. One way that can be done in order to prevent the environment to being free of dengue wiggler is through some sort of surveys.

This monitoring system is designed using Waterfall methodology using the programming language such as Javascript, PHP, CodeIgniter framework, AngularJS, and Ionic also using MySQL database. A needs analysis conducted by interviewing one of the members of Center of Desease Control's member and the Village Head of Muktiharjo so that the design could be done, appropriate and well targeted.

The results of the final project is mobile and desktop applications that can change the performance of the JUMANTIK (Mosquito Eradication Officers) with more modern, neat, and systematic application so that the data obtained can meet the desired needs. The system that has been designed has been tested using black-box method and the results of these tests indicate that all the functions contained in this system has worked well.
\end{abstract}

Keywords: Android, Application, Mobile, Information Systems, wiggler.

\section{PENDAHULUAN}

$\mathrm{B}^{\mathrm{s}}$ eberapa dekade terakhir ini, insiden DBD menunjukkan peningkatan yang sangat pesat di seluruh penjuru dunia. Sebanyak Dua setengah milyar atau dua perlima penduduk dunia beresiko terserang demam dengue. Sebanyak 1,6 milyar $(52 \%)$ dari penduduk yang beresiko tersebut hidup di wilayah Asia Tenggara. WHO memperkirakan sekitar 50 juta kasus infeksi dengue tiap tahunnya.

Berbagai metode pemberantasan habitat nyamuk ini, misalnya dengan upaya Pemberantasan Sarang Nyamuk (PSN), masih dianggap cara paling efektif. Berkaitan dengan hal tersebut pemerintah memiliki program kajian yaitu dengan melakukan survei jentik pada rumah-rumah warga. JUMANTIK kepanjangan dari JUru PeMANtau JenTIK merupakan seorang petugas khusus yang secara sukarela mau bertanggung jawab untuk melakukan upaya pemantauan jentik nyamuk DBD Aedes Aegypti di wilayah-wilayah dengan sebelumnya melakukan pelaporan ke kelurahan atau puskesmas terdekat.

Perkembangan teknologi informasi dapat meningkatkan kinerja dan memungkinkan berbagai kegiatan dapat dilaksanakan dengan cepat, tepat dan akurat, sehingga akhirnya akan meningkatkan produktivitas. Perkembangan teknologi informasi memperlihatkan bermunculannya berbagai jenis kegiatan yang berbasis pada teknologi ini, seperti $e$ government, e-commerce, e-education, emedicine, $e$ laboratory, dan lainnya, yang kesemuanya itu berbasiskan elektronika.

\section{KAJIAN PUSTAKA}

\section{A Teknologi Informasi}

Teknologi Informasi adalah teknologi yang mampu membantu manusia untuk melakukan pekerjaan mereka. Teknologi Informasi (Information Technology) merupakan dari bahasa latin 'texere' atau yang berarti membangun. Teknologi sebenarnya memiliki 2 aspek penting, yaitu hardware (perangkat keras) dan software (perangkat lunak).[1]

Dari kedua komponen tersebut, mereka saling berkaitan satu sama lain yang berguna untuk bekerja sama menciptakan sebuah teknologi informasi. Namun Teknologi lebih dominan pada hardware atau perangkat keras, namun software juga memiliki peranan yang sangat penting. Teknologi Informasi, sering dikaitkan dengan teknologi komunikasi. Karena keduanya memang saling berhubungan satu sama lain. Pada dasarnya, teknologi komunikasi dan teknologi informasi memiliki definisi yang sama. Teknologi komunikasi berarti semua teknologi informasi yang mendukung semua teknologi komunikasi.

B Pemetaan

Definisi dari pemetaan menurut Juhadi dan Liesnoor (2001) adalah tahapan yang harus dilakukan dalam pembuatan peta. Langkah awal yang dilakukan dalam pembuatan data, dilanjutkan dengan pengolahan data, dan penyajian dalam bentuk peta.

Jadi pemetaan dapat diartikan sebagai proses pengukuran, perhitungan dan penggambaran permukaan bumi dengan menggunakan cara atau metode tertentu untuk mendapatkan gambaran permukaan bumi yang didasarkan dengan 2 koordinat letak bumi yaitu latitude dan longitude. ${ }^{[2]}$

C Mobile Device

Mobile Device (juga dikenal dengan istilah cellphone, handheld device, handheld computer, "Palmtop", atau secara sederhana disebut dengan handheld) adalah alat penghitung (computing device) yang berukuran saku. Ciri khasnya mempunyai layar tampilan (display screen) dengan layar sentuh atau keyboard mini. Dalam hal PDA (Personal Digital Assistant) masukan (input) dan keluaran (output) dikombinasi dalam interface layar sentuh.

Terdapat beberapa sistem operasi mobile device yang popular di pasaran saat ini, seperti : Symbian, iOS, Linux, dan Windows Mobile. 
Untuk mendapatkan pelayanan dan kenyamanan dari sebuah komputer konvensional yang dapat dibawa-bawa dan praktis adalah smartphone dan PDA. Kedua peralatan ini yang paling populer, selain itu ada Enterprise Digital Assistants yang dapat dikembangkan lebih jauh untuk kepentingan bisnis, yang menawarkan peralatan yang mampu mengambil data terintegrasi seperti Bar Code, RFID dan Smart Card.

D Android

Android merupakan sistem operasi telepon seluler yang tumbuh di tengah sistem operasi lainnya yang berkembang dewasa ini. Sistem Operasi lainnya seperti Windows Mobile, iOS-iPhone, Symbian, dan masih banyak lagi juga menawarkan kekayaan isi dan keoptimalan berjalan di atas perangkat keras yang ada. Akan tetapi, sistem operasi yang ada ini berjalan dengan memprioritaskan aplikasi inti yang dibangun sendiri tanpa melihat potensi yang cukup besar dari aplikasi pihak ketiga. Oleh karena itu adanya keterbatasan dari aplikasi pihak ketiga untuk mendapatkan data asli ponsel, berkomunikasi antar proses serta keterbatasan distribusi aplikasi pihak ketiga untuk platform mereka. ${ }^{[4]}$

Android menawarkan sebuah lingkungan yang berbeda untuk pengembang. Setiap aplikasi memiliki tingkatan yang sama. Android tidak membedakan antara aplikasi inti dengan aplikasi pihak ketiga. API yang disediakan menawarkan akses ke perangkat keras, maupun data-data ponsel sekaligus, atau data sistem sendiri. Bahkan, pengguna dapat menghapus aplikasi inti dan menggantinya dengan aplikasi pihak ketiga. ${ }^{[10]}$ E Kerangka Kerja Ionic

Ionic adalah kerangka kerja Mobile HTML5 untuk mengembangkan aplikasi perangkat bergerak lintas-platform hybrid native menggunakan HTML, JavaScript dan CSS.

Ionic dikembangkan untuk memudahkan pengembang mengembangkan aplikasi perangkat bergerak hybrid native daripada membuat situs perangkat bergerak. Ionic merupakan kerangka kerja yang fokus pada interaksi dengan pengguna melalui HTML5 tetapi dengan kecepatan aplikasi native. Ionic tidak menggunakan kerangka kerja CSS Bootstrap maupun library JavaScript jQuery mobile melainkan menggunakan kerangka kerja JavaScript angularJS yang mempunyai kecepatan proses lebih cepat dari jQuery mobile.

\section{F Genymotion}

Genymotion merupakan sebuah aplikasi emulator android yang lebih mudah digunakan dan memiliki lebih banyak fungsi dibanding generasi genymotion sebelumnya. Genymotion memiliki performa yang cepat sehingga tidak menyulitkan ketika digunakan. ${ }^{[6]}$

Genymotion dibangun berdasarkan proyek open-source sebelumnya yakni AndroVM, untuk memberikan lingkungan android yang realistis dan berfungsi penuh berdasarkan berbagai ponsel dan tablet yang berbeda. ${ }^{[9]}$ Untuk dapat menggunakan Genymotion, user harus mendaftar untuk mendapatkan akun gratis Genymotion sebelum user dapat mulai download mesin virtual Genymotion.

\section{$G \quad$ Sistem Monitoring}

Definisi dari sistem monitoring dapat dibagi dalam beberapa bagian aspek, antara lain :

- George R. Tery (2006), mengartikan bahwa sistem monitoring merupakan usaha untuk mendeterminasi apa yang telah dilaksanakan, maksudnya mengevaluasi prestasi kerja dan apabila perlu, menerapkan tidankan-tindakan korektif sehingga hasil pekerjaan sesuai dengan rencana yang telah ditetapkan.
- (WHO) Monitoring adalah suatu proses pengumpulan dan menganalisis informasi dari penerapan suatu program termasuk mengecek secara reguler untuk melihat apakah kegiatan/program itu berjalan sesuai rencana sehingga masalah yang dilihat /ditemui dapat diatasi.

Jadi, sistem monitoring dapat diartikan sebagai kegiatan pengawasan yang berarti proses pengamatan, pemeriksaan, pengendalian dan pengoreksian dari seluruh kegiatan organisasi. $^{[7]}$

\section{PERANCANGAN SISTEM}

\section{A Analisis Kebutuhan}

Penyusunan analisis kebutuhan dilakukan untuk mengurangi risiko sistem gagal dikembangkan. Kegagalan pengembangan sistem umumnya terjadi karena sistem tidak memenuhi kebutuhan pengguna atau sistem tidak sesuai dengan proses bisnis yang berjalan. Studi kelayakan perlu dilakukan dalam penyusunan analisis kebutuhan untuk menghindari risiko tersebut. Studi kelayakan dapat dilakukan dengan cara wawancara, observasi dan membaca dokumen. Hasil analisis kebutuhan berupa dokumen System Requirements Specifications (SRS). Pengembangan ini menggunakan struktur SRS tersebut untuk menyampaikan analisis kebutuhan.

\section{1) Kondisi Awal}

Proses selama wawancara dan observasi memberikan gambaran kondisi yang terjadi dilapangan. Pada proses monitoring jentik nyamuk, terdapat beberapa aktivitas yang harus dilakukan. Flowchart aktivitas kondisi awal proses pengadaan monitoring jentik nyamuk pada suatu daerah ditunjukkan pada Gambar 1.

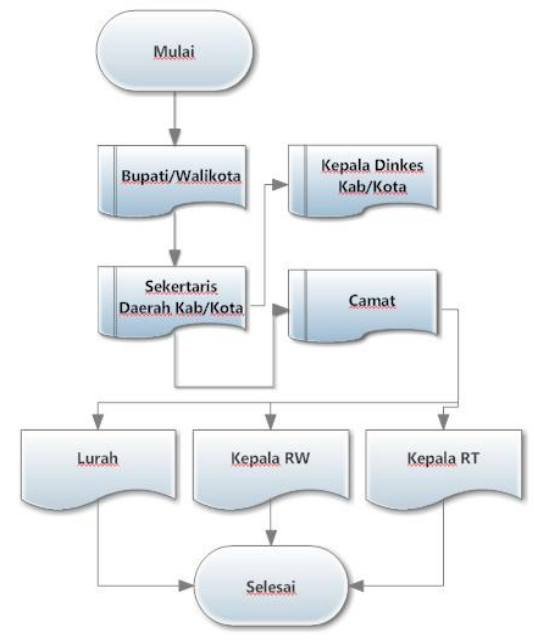

Gambar 1 flowchart pengadaan monitoring

Dari flowchart pada Gambar 1 menunjukan bahwa Bupati/Walikota melalui sekretaris daerah merupakan koordinator utama yang membangun kerjasama di antara instansi terkait dinas kesehatan dan camat setempat. Kerjasama tersebut diwujudkan dalam wadah Kelompok Kerja (Pokja) PSN (Pemberantasan Sarang Nyamuk).

Daerah yang telah memiliki wadah Kelompok Kerja Operasional (Pokjanal) DBD maka Pokja PSN DBD dapat dimasukan sebagai bagian dari Pokjanal DBD yang sudah ada. Bupati/Walikota berwenang dan bertanggungjawab dalam mengeluarkan ketetapan pembentukan Pokja Jumantik-PSN DBD di wilayahnya melalui sebuah surat keputusan. 
Deskripsi Umum Sistem

Deskripsi umum sistem diperlukan untuk menjelaskan perspektif aplikasi dari sistem monitoring jentik nyamuk, fungsi aplikasi yang diharapkan untuk berjalan, kelompok pengguna aplikasi, lingkungan pengoperasian serta lingkungan pengguna yang akan menggunakan sistem.

1. Perspektif Aplikasi

Aplikasi sistem monitoring jentik nyamuk adalah aplikasi yang digunakan oleh anggota JUMANTIK (JUru PeMANtau JenTIK) dalam melakukan manajemen pengawasan jentik nyamuk pada suatu daerah. Aplikasi tersebut digunakan untuk mengelola data aktivitas perkembangan jentik nyamuk di daerah tertentu.

2. Fungsi Produk

Aplikasi dapat memasukkan data laporan suatu rumah yang berisikan informasi tentang perkembangan jentik nyamuk pada rumah tersebut. Pengolahan data dilakukan lebih cepat menggunakan komputer. Data yang disimpan dalam sistem dapat diolah untuk menghasilkan laporan.

3. Kelompok Pengguna

Pengguna yang menggunakan aplikasi sistem monitoring jentik nyamuk ini terdiri dari 2 jenis, yang pertama yaitu :

a. Pengguna admin atau operator manajemen data sistem monitoring jentik nyamuk. Pengguna kedua adalah petugas JUMANTIK. Kedua pengguna tersebut memiliki aktivitas yang berbeda dalam menggunakan sistem monitoring jentik nyamuk. Pengguna admin atau operator adalah pengguna yang bertugas untuk melakukan pengolahan data yang didapatkan dari lapangan dan juga data semua petugas. Pengguna Admin memiliki hak paling tinggi dalam manajemen sistem monitoring ini, sedangkan operator hanya memiliki hak untuk memantau aliran dan perubahan data yang terjadi pada sistem.

b. Pengguna petugas (surveyor) adalah pengguna yang bertugas untuk melakukan aktivitas pencatatan informasi responden di lapangan. Pengguna petugas merupakan karyawan atau para Juru Pemantau Jentik (JUMANTIK) dari Dinas Kesehatan setempat.

4. Lingkungan Pengoprasian

Aplikasi sistem monitoring jentik nyamuk ini dioperasikan di Dinas Kesehatan setempat. Aplikasi ini masih bersifat uji coba, sehingga data masukan dan keluaran masih dilakukan secara local atau belum menggunakan hosting.

5. Lingkungan Pengguna

Pada sisi admin aplikasi berupa aplikasi yang berbasis desktop. Pengguna hanya bisa mengakses aplikasi ini pada komputer tertentu yang sudah disetujui untuk digunakan sebagai sisi server aplikasi, sedangkan pada sisi pengguna petugas (surveyor) aplikasi berupa ponsel pintar yang telah dipasang sebelumnya.

3) Kebutuhan Fungsional

Sistem yang dikembangkan diharapkan dapat memenuhi kebutuhan fungsional agar dapat digunakan sesuai dengan proses yang telah berjalan pada sisi pengelola data dan petugas JUMANTIK. Berikut adalah kebutuhan fungsional yang harus dipenuhi oleh sistem;
1. Sistem pada sisi admin dapat menyimpan, mengubah, dan menghapus data responden. Fungsi tersebut bertujuan agar data responden dapat diolah atau dimenejemen dengan baik sehingga dapat menjadi data yang falid.

2. Sistem pada sisi admin dapat menyimpan, mengubah, dan menghapus data pegawai. Fungsi tersebut bertujuan agar data pegawai yang ada dapat dimonitoring dan dipantau ketika pegawai sedang berada dilapangan.

3. Sistem pada sisi operator dapat melihat proses kerja yang berlangsung, namun tidak dapat mengubah data yang sudah ada. Fungsi ini bertujuan untuk memantau pegawai dalam melaksanakan pekerjaannya dan juga memantau admin ketika admin melakukan perubahan data pegawai atau data lapangan.

4. Sistem pada sisi operator dapat melihat log login yang terjadi dilapangan maupun disisi admin. Fungsi ini bertujuan untuk memantau admin dan pegawai mana saja yang telah melakukan login pada hari tertentu.

5. Sistem pada sisi petugas dapat memasukkan dan melihat data hari ini yang telah di input. Fungsi ini bertujuan agar data responden yang telah didicatat dapat dilihat kembali oleh petugas.

6. Sistem pada sisi petugas tidak dapat mengubah data responden yang telah didata sebelumnya. Fungsi ini bertujuan untuk meminimalisasi kesalahan dalam memasukkan data di lapangan.

4) Kebutuhan Non-Fungsional

Selain kebutuhan fungsional sistem juga harus memenuhi kebutuhan non-fungsional agar sistem yang berjalan dapat digunakan dengan baik oleh pengguna pada sisi admin, operator maupun sisi petugas JUMANTIK. Berikut merupakan kebutuhan non-fungsional yang harus dipenuhi oleh sistem.

1. Kebutuhan Perangkat Keras

Sistem berjalan dengan posisi server berada di MySQL localhost/phpmyadmin. Dengan arsitektur tersebut maka kebutuhan perangkat keras untuk server dapat sepenuhnya diabaikan untuk mendukung platform yang akan dikembangkan.

Sedangkan untuk sisi petugas aplikasi monitoring jentik nyamuk memerlukan PC yang dapat digunakan untuk menjalankan aplikasi desktop, dari berbagai macam kebutuhan minimal aplikasi desktop, maka perangkat keras yang dibutuhkan pada sisi admin adalah sebagai berikut:

- Prosesor : Intel Pentium 4

- RAM : $512 \mathrm{MB}$

- HDD : $4 \mathrm{~GB}$

Untuk sistem yang berjalan pada pengguna petugas JUMANTIK memerlukan perangkat bergerak dengan spesifikasi minimal sebagai berikut :

- Ponsel pintar android versi 4.0 (ICS)

- RAM 512 MB

- HDD 4 GB

2. Kebutuhan Perangkat Lunak

Aplikasi membutuhkan perangkat lunak pendukung agar aplikasi bisa berjalan di server. Kebutuhan minimal perangkat lunak server adalah :

- MySQL phpMyAdmin

Petugas JUMANTIK pengguna aplikasi monitoring jentik nyamuk juga memerlukan perangkat lunak pendukung 
untuk bisa mengakses aplikasi. Kebutuhan minimal perangkat lunak petugas JUMANTIK adalah :

- Ponsel pintar dengan dukungan Javascript.

Perangkat yang digunakan oleh petugas JUMANTIK memerlukan perangkat lunak pendukung untuk bias menggunakan aplikasi yang dikembangkan. Kebutuhan minimal perangkat lunak petugas JUMANTIK adalah menggunakan Sistem Operasi Android versi 4.0 disesuaikan dengan kebutuhan minimal kerangka kerja Ionic yang digunakan untuk mengembangkan sistem.

3. Operasional

a. Sistem yang bekerja pada aplikasi monitoring jentik nyamuk dapat diakses dari perangkat komputer dan ponsel pintar.

b. Sistem memiliki fitur dan kegunaan yang berbeda dalam fungsi yang dijalankan di perangkat komputer dan ponsel pintar.

c. Aplikasi membutuhkan koneksi internet.

4. Keamanan

a. Sistem memiliki fungsi login untuk memberikan akses ke pengguna.

b. Sistem memiliki role untuk membedakan hak pengguna.

c. Sistem mengimplementasikan metode soft delete untuk menjaga validasi data petugas.

Desain Sistem

SRS (Software Requirements Specification) yang dihasilkan dari analisis kebutuhan digunakan sebagai bahan perancangan sistem. Kebutuhan fungsional di dalam SRS menentukan bagaimana sistem harus dibangun sehingga mampu memenuhi kebutuhan yang diharapkan. Spesifikasi teknis dibuat pertama kali dalam perancangan untuk menetapkan lingkungan pengembangan. Pemodelan dilakukan setelah spesifikasi sistem selesai ditentukan. Penulisan kode belum bisa dimulai sebelum pemodelan selesai dibuat. Penulisan kode tanpa memperhatikan pemodelan akan menimbulkan risiko kegagalan pengembangan. Desain antarmuka dilakukan setelah pemodelan selesai dibuat sehingga sistem mampu dioperasikan pengguna dengan mudah. Pengembangan aplikasi yang mengabaikan desain antarmuka user friendly cenderung susah digunakan.

1) Spesifikasi Teknis

1. Arsitektur Sistem

Sistem yang dikembangkan berupa aplikasi berbasis desktop dan aplikasi ponsel pintar. Server desktop dibutuhkan untuk menjalankan aplikasi tersebut. Data yang diolah sistem disimpan pada basis data. Server basis data juga dibutuhkan untuk menjalankan basis data yang digunakan sistem. Admin aplikasi sistem monitoring jentik nyamuk dapat mengakses aplikasi desktop yang sudah ditanam pada komputer tertentu sebelumnya.

Admin aplikasi sistem monitoring jentik nyamuk mengakses data melalui basis data server yang berada pada MySQL localhost/phpmyadmin/, sedangkan petugas diharuskan memasang aplikasi sistem monitoring jentik nyamuk pada perangkat bergerak sebelumnya di masingmasing ponsel pintar mereka.

2. Arsitektur Aplikasi

Deskripsi umum SRS menjelaskan bahwa sistem berupa aplikasi desktop pada sisi admin aplikasi monitoring jentik nyamuk dan aplikasi perangkat bergerak pada petugas aplikasi monitoring jentik nyamuk. Arsitektur yang digunakan untuk membangun aplikasi tersebut adalah aplikasi client/server. Bahasa yang dipakai adalah PHP dengan kerangka kerja CodeIgniter 3.0, Javascript dengan kerangka kerja AngularJS dan Ionic..

2)

Desain ERD

Sistem yang dikembangkan merupakan sistem yang berfungsi untuk mengolah data. Pemodelan perlu dilakukan untuk menentukan data yang diolah. Pemodelan tersebut dilakukan setelah spesifikasi teknis ditentukan. ERD digunakan untuk memodelkan data yang akan disimpan dalam basis data. Langkah yang dilakukan dalam merancang ERD adalah menentukan entitas yang ada, lalu entitas tersebut dihubungkan dalam notasi diagram.

1. Menentukan Entitas

Entitas dapat ditentukan dari SRS. Kebutuhan yang dijelaskan memberikan gambaran data-data yang diolah. Data tersebut merupakan entitas yang akan digunakan dalam merancang ERD. Tabel 1 menunjukkan entitas yang telah ditentukan.

Tabel 1 Tabel Entitas ERD

\begin{tabular}{|l|l|l|}
\hline No & Nama & \multicolumn{1}{|c|}{ Keterangan } \\
\hline 1. & Data_Input & Data - data responden. \\
\hline 2. & Data_JenisTPA & $\begin{array}{l}\text { Data - data yang berkaitan dengan } \\
\text { jumlah dan jenis TPA yang dimiliki } \\
\text { oleh responden. }\end{array}$ \\
\hline 3. & User & $\begin{array}{l}\text { Data - data yang berkaitan dengan } \\
\text { informasi petugas yang diklasifikasikan } \\
\text { menurut peranannya yaitu, admin, } \\
\text { operator dan petugas. }\end{array}$ \\
\hline 4. & Data_Login & $\begin{array}{l}\text { Data - data yang berisi tentang } \\
\text { informasi log } \text { user ketika mengakses } \\
\text { sistem. }\end{array}$ \\
\hline
\end{tabular}

\section{Menggambar Diagram}

Diagram dapat digambarkan setelah seluruh entitas didefinisikan beserta atributnya. Tujuan dari diagram adalah untuk menjelaskan hubungan antara entitas yang telah ditentukan. Relasi yang digambarkan dapat diperjelas dengan menambahkan informasi kardinalitas antara entitas. Berikut ini adalah diagram yang digambarkan berdasarkan atribut yang ada.

- Relasi Entias Data_Input

Gambar 2 menunjukkan hubungan antara entitas data_input dengan entitas data_jmltpa dan user. Entitas data_input merupakan salah satu entitas utama yang diolah dalam sistem ini yang memuat semua informasi responden berikut dengan jenis TPA yang telah disurvey oleh petugas. 


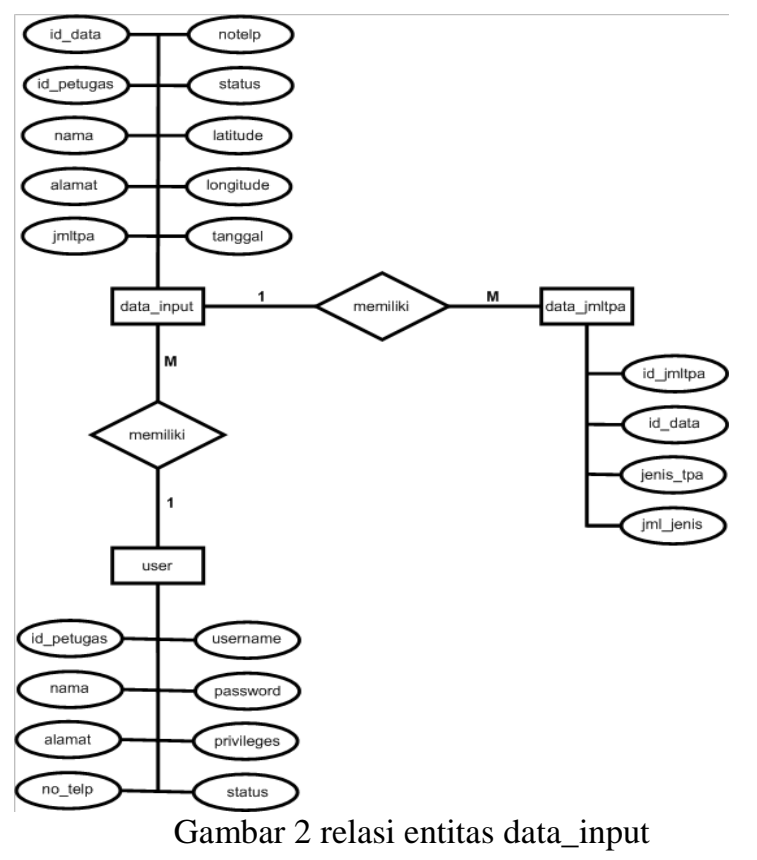

- Relasi Entitas User

Gambar 3 menunjukkan hubungan antara entitas user dengan entitas data_login. Entitas ini termasuk hubungan many to many.

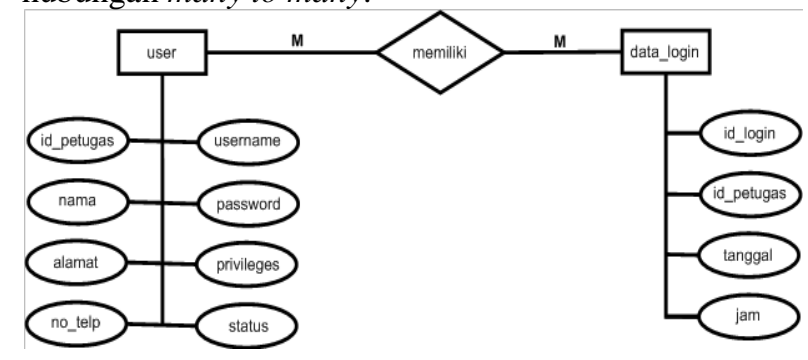

Gambar 3 relasi entitas user

3. Diagram Use Case Sistem

Bagaimana pengguna menggunakan sistem dapat digambarkan dengan diagram use case. Diagram use case dibuat berdasarkan skenario yang dilakukan pengguna ketika menggunakan fungsi sistem. Diagram use case terlihat pada Gambar 4.

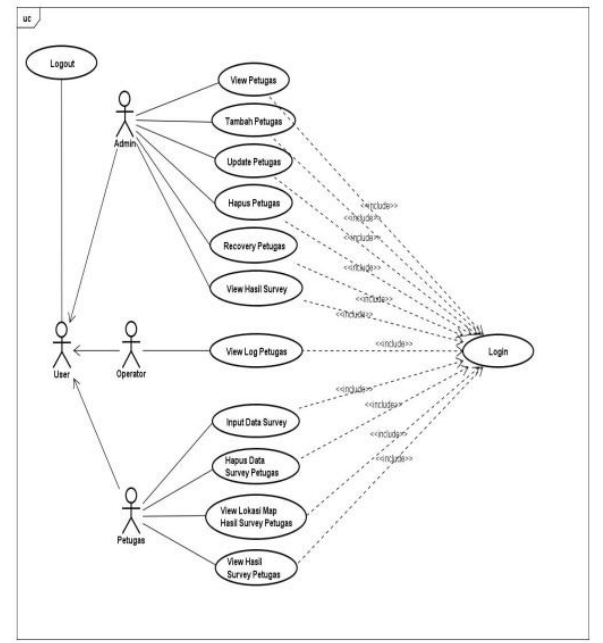

Gambar 2 Diagram Use Case Sistem
Pemodelan diagram use case menunjukkan bahwa sistem memiliki 3 aktor yang menggunakan sistem. Sistem memiliki tiga belas skenario umum..

4. Diagram kelas

Diagram kelas pada gambar 5 menunjukkan kelas dengan atribut yang saling terhubung dengan kelas lain.

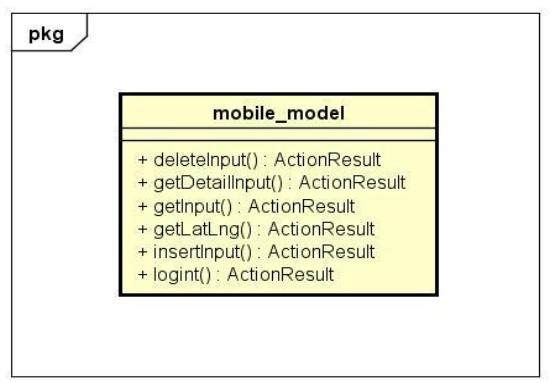

Gambar 3 Diagram kelas tipe model keseluruhan sistem (mobile)

Kelas yang ada pada Gambar 5 tersebut merupakan kelas dengan tipe model yang berfungsi sebagai abstraksi basis data. Semua model yang ada merupakan extend dari repository yang berfungsi sebagai penghubung dengan kelas tipe controller.

Diagram kelas pada gambar 6 menunjukkan kelas controller yang berfungsi sebagai pengolah Business logic.

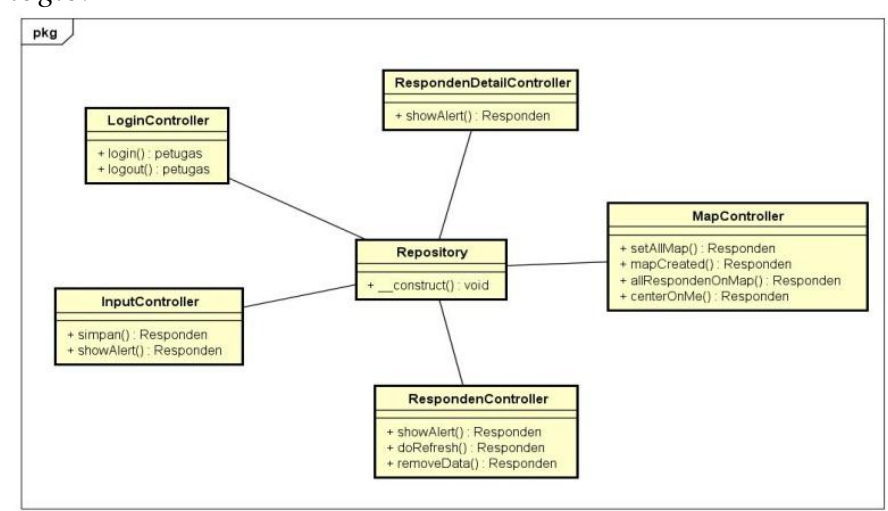

Gambar 4 Diagram kelas tipe controller keseluruhan sistem

Kelas controller dapat berinteraksi dengan data di dalam basis data dengan Repository Pattern. Deskripsi masing masing kelas ditunjukkan pada tabel 2.

Tabel 2 Deskripsi diagram kelas

\begin{tabular}{|l|l|l|}
\hline No & Kelas & Deskripsi \\
\hline 1 & Mobile_model & $\begin{array}{l}\text { Model data pengguna petugas dan data } \\
\text { responden }\end{array}$ \\
\hline 2 & Repository & $\begin{array}{l}\text { Kelas yang digunakan oleh controller } \\
\text { untuk mengakses model }\end{array}$ \\
\hline 3 & LoginController & Controller yang mengelola data petugas \\
\hline 4 & InputController & $\begin{array}{l}\text { Controller yang mengelola input data } \\
\text { responden }\end{array}$ \\
\hline 5 & RespondenController & $\begin{array}{l}\text { Controller yang mengelola data } \\
\text { responden }\end{array}$ \\
\hline 6 & $\begin{array}{l}\text { RespondenDetailCon } \\
\text { troller }\end{array}$ & $\begin{array}{l}\text { Controller yang mengelola detail data } \\
\text { responden }\end{array}$ \\
\hline 7 & MapController & $\begin{array}{l}\text { Controller yang mengelola data lokasi } \\
\text { responden }\end{array}$ \\
\hline
\end{tabular}

Pemodelan yang dibuat sudah cukup untuk digunakan untuk menjelaskan sistem akan memenuhi kebutuhan sistem. Diagram aktivitas memberikan gambaran utama bagaimana sistem akan digunakan dalam proses bisnis. Diagram use case 
memberikan informasi bagaimana pengguna dalam menggunakan sistem. Diagram sequence menampilkan perilaku sistem ketika digunakan oleh pengguna. Diagram kelas menunjukkan struktur sistem.

Kode yang digunakan untuk membangun aplikasi bias dikerjakan tahap ini. Spesifikasi teknis dan pemodelan dapat memberikan gambaran dan arahan bagaimana kode ditulis. Penulisan kode kemudian dikerjakan hingga selesai.

\section{PENGUJian UnIT}

Pengujian unit dilakukan dalam pengujian sistem ini. Pengujian unit adalah melakukan analisis dari masing - masing fungsi di dalam sistem. Tujuan pengujian unit adalah membatasi objek pengujian dalam skala kecil sehingga tahap perbaikan akan lebih cepat jika ditemukan kesalahan. Pengujian unit dilakukan dengan menjalankan setiap fungsi di dalam sistem. Teknik yang digunakan dalam pengujian unit ini adalah teknik kotak hitam. Teknik tersebut adalah teknik untuk memastikan masing - masing fungsi individu berjalan dengan cara diamati ketika fungsi dieksekusi.:

\section{Login sistem}

Login sistem adalah aktivitas yang dilakukan ketika memulai akses ke dalam sistem. Pengujian dilakukan dengan memasukkan username dan password pada form login yang ditunjukkan pada Gambar 7 .

$$
\text { Login }
$$

Selamat Datang Di Monitoring Sistem
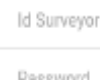

Masuk

Gambar 5 Pengujian integrasi login sistem

Data ternak baru yang dibuat oleh operator menjadi data ternak yang akan dilakukan pengawasan ternak oleh petugas pengawasan sesuai dengan data ternak yang telah dibuat.

2. Membuat Data Responden

Membuat data responden adalah kegiatan untuk membuat laporan data dari rumah responden yang sudah dimonitoring atau disurvey akan keberadaan jentik nyamuk di tiap penyimpanan yang ada di rumah masing-masing responden sebelumnya. Pengujian dilakukan dengan memasukkan data responden baru pada form data yang ditunjukkan pada Gambar 8.

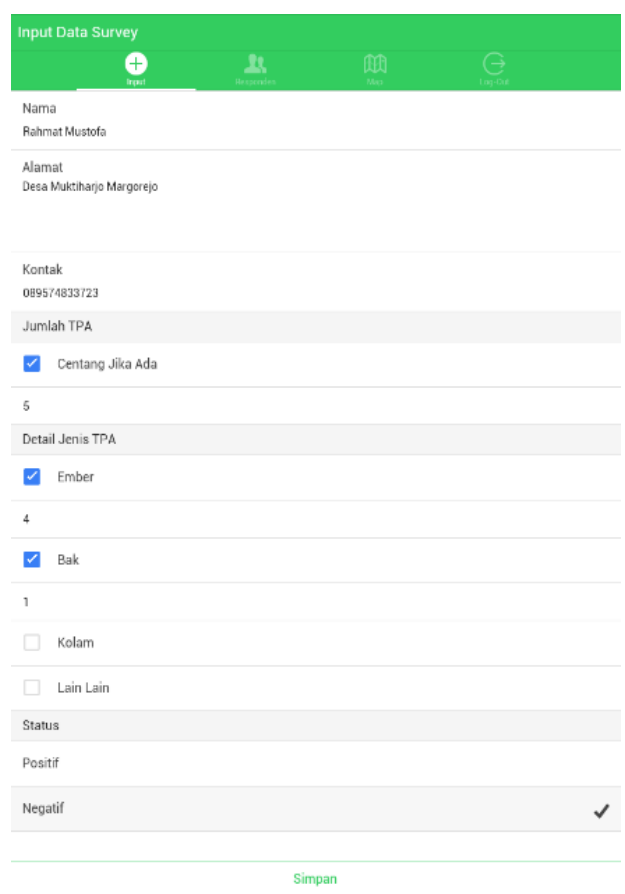

Gambar 8 Pengujian integrasi input responden

3. Melihat Responden

Melihat data responden digunakan ketika petugas sudah berhasil memasukkan data - data berkaitan tentang responden sebelumnya. Pengujian dilakukan dengan menekan tab dengan gambar "people" yang bertuliskan responden. Gambar 9 menunjukkan tampilan awal ketika petugas sudah berhasil memasukkan data responden.

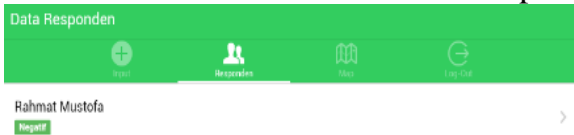

Gambar 9 Pengujian integrasi lihat responden

\section{Melihat Detail Responden}

Melihat detail data responden dilakukan pengguna untuk melihat apakah data yang telah dimasukkan sudah benar falid berdasarkan informasi yang diberikan oleh responden dengan cara menekan nama responden di tab responden. Gambar 10 menunjukkan tampilan detail data responden. 


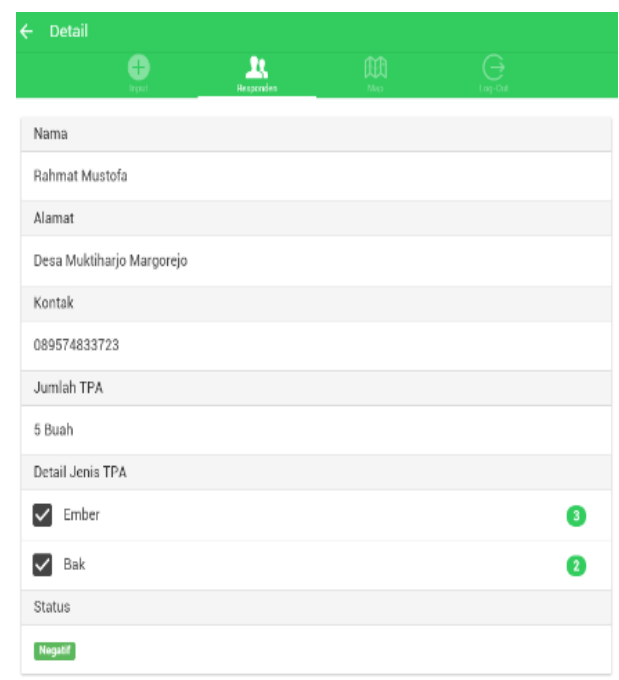

Gambar 10 Pengujian integrasi detail responden

5. Menghapus Data Responden

Menghapus data responden adalah kegiatan ketika data yang telah dimasukkan oleh pengguna memiliki kesalahan ketika data dimasukkan. Pengujian ini dilakukan dengan menggeser nama responden pada tab responden kearah kiri, kemudian akan keluar pilihan untuk menghapus data responden. Gambar 11 menunjukkan form konfirmasi yang muncul ketika akan menghapus data responden.

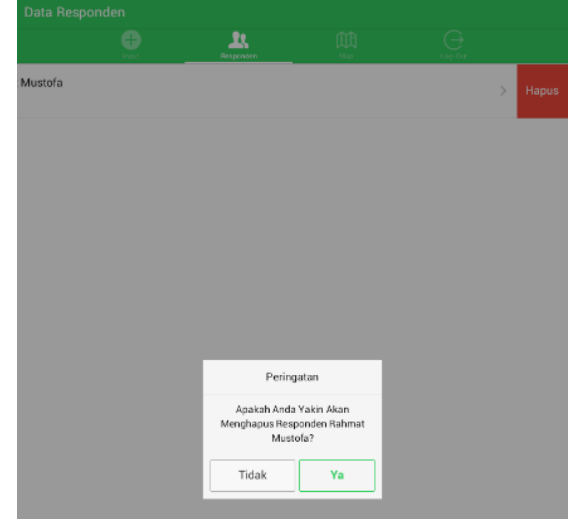

Gambar 11 Pengujian integrasi Hapus Responden

6. Melihat Lokasi Responden

Melihat lokasi responden adalah kegiatan pengguna ketika ingin mencari tahu lokasi detail tentang responden yang sudah didata sebelumnya dari mulai latitude dan longitude dengan membuka tab map pada aplikasi perangkat bergerak. Gambar 12 menunjukkan tampilan lokasi responden didalam map yang telah didata sebelumnya.

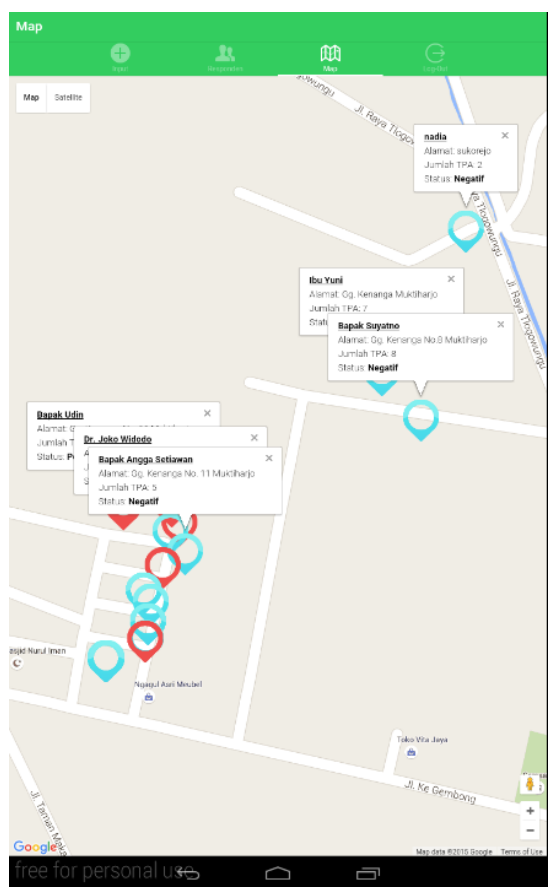

Gambar 12 Pengujian Integrasi Lokasi Responden

7. Pengujian Integrasi Pada Aplikasi Desktop

Data yang telah dimasukkan oleh petugas lapangan pada hari itu, akan langsung masuk ke dalam basis data dan akan tercantum pada halaman admin. Sekali lagi disini admin dan operator hanya dapat membaca data responden yang telah masuk untuk menjaga keaslian data yang telah dimasukkan oleh petugas surveyor. Gambar 13 menunjukkan hasil data responden yang diterima oleh admin dan operator dari petugas.

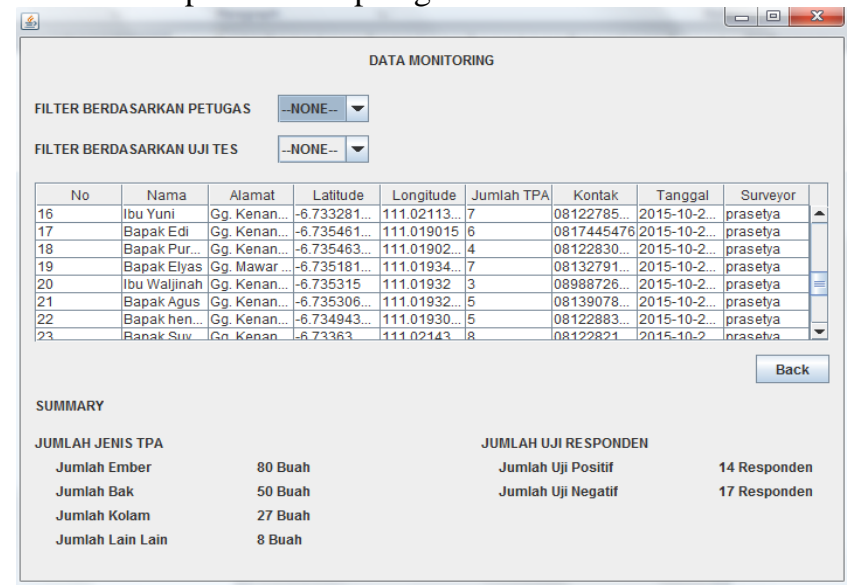

Gambar 13 Pengujian integrasi menampilkan data responden

Skenario yang dijalankan menjelaskan bahwa sistem dapat mengintegrasikan unit dalam sistem untuk melakukan pekerjaan. Skenario yang diuji ditampilkan detail dengan fungsi terkait pada tabel 3 .

Tabel 3 Hasil skenario pengujian integrasi

\begin{tabular}{|l|l|l|}
\hline Skenario & Fungsi Terkait & Analisis \\
\hline $\begin{array}{l}\text { Admin aplikasi } \\
\text { monitoring jentik } \\
\text { nyamuk }\end{array}$ & Login, membuat petugas baru & Berhasil \\
\hline $\begin{array}{l}\text { Petugas } \\
\text { melakukan login }\end{array}$ & $\begin{array}{l}\text { Login, memasukan username dan } \\
\text { password }\end{array}$ & Berhasil \\
\hline $\begin{array}{l}\text { Operator melihat } \\
\text { log data login }\end{array}$ & $\begin{array}{l}\text { Login, memilih menu log data login } \\
\text { pada halaman awal, melihat log data } \\
\text { login tentang petugas mana saja yang } \\
\text { telah mengakses sistem pada waktu }\end{array}$ & Berhasil \\
\hline
\end{tabular}




\begin{tabular}{|l|l|l|}
\hline & tertentu. & \\
\hline Petugas & Login, melihat laporan data responden & Berhasil \\
melakukan & yang telah masuk hasil dari pendataan & \\
pembacaan data & petugas surveyor, melakukan filter & \\
responden dari & berdasarkan petugas, melakukan filter & \\
petugas surveyor. & berdasarkan uji tes. & \\
\hline
\end{tabular}

Tahap pengujian yang dilakukan menunjukkan sistem memiliki fungsi yang bekerja dengan benar.

\section{$\mathrm{V}$ PENUTUP}

\section{A Kesimpulan}

Selama pengembangan sistem ini terdapat beberapa hal yang bisa disimpulkan. Kesimpulan yang didapatkan antara lain:

1. Aplikasi mobile monitoring jentik nyamuk dapat mengolah data responden dengan resiko data hilang atau rusak lebih kecil daripada metode sebelumnya.

2. Aplikasi mobile monitoring jentik nyamuk memiliki fitur yang lebih detail dalam pendataan data responden daripada sebelumnya.

3. Sistem yang dikembangkan dapat mengolah data masukan responden sehingga dapat mengurangi ketidakcocokan data responden yang diolah dibandingkan metode konvensional.

4. Sistem yang dikembangkan lebih tertata dan terorganisir dalam pendataan data responden yang dilakukan.

5. Aplikasi desktop memiliki fitur untuk memisahkan dan membedakan privileges antara admin, operator, dan petugas lapangan.

6. Survey yang dilakukan di Desa Muktiharjo menghasilkan data tentang daerah yang berpotensi untuk terjadinya penyebaran penyakit demam berdarah berdasarkan perhitungan angka kepadatan jentik dengan menggunakan metode Visual.

7. Density Figure yang didapatkan di Desa Muktiharjo melebihi angka 5 pada intepretasi hasil pengukuran jentik yang menunjukkan bahwa Desa Muktiharjo dalam keadaan daerah merah dengan status derajad penularan penyakit oleh larva tinggi dan membutuhkan pengendalian dengan segera.

\section{B. Saran}

1. Sistem informasi ini memiliki banyak ruang untuk dikembangkan seperti pengelolaan data responden berkala dan statistic manajemen kesehatan rumah responden jentik nyamuk.

2. Aplikasi dapat dikembangkan menjadi hosting dengan tampilan dan fungsi admin yang lebih banyak agar dapat memanajemen daerah yang lebih luas.

\section{DAFTAR PUSTAKA}

[1] Aji, Supriyanto, 2005, Pengantar Teknologi Informasi, Jakarta, Salemba Infotek.

[2] Novak, J, 2004, Introduction To Concept and Varieties of Mapping. Pensacola, Florida.

[3] Djojo, M, 2000, Perkembangan Internet Pada Mobile Device, Article Technologies, Bandung. Gava Media.

[4] Siregar, Ivan Michael, 2011, Membongkar Source Code Berbagai Aplikasi Android, Elexmedia Komputindo, Jakarta.

[5] Ionic Framework, Online at http://ionicframework.com/docs/guide/preface.html, diakses tanggal 8 April 2015.

[6] Echessa, Joyce, 2014, Level Up Your Web AppsWith GO, Nairobi, Kenya.

[7] Manai, Syamsudin, 2013, 60 Menit Belajar Monitoring Jaringan (Cacti), Jakarta, BukuDigial.net.

[8] driftyco, "What is Ionic" 2014, Online. Available: https://github.com/driftyco/ionic. diakses tanggal 29 September 2015.

[9] Phillips, Bill, 2014, “Android Programming: The Big Nerd Ranch Guide", Big Nerd Ranch, LLC.

[10] Huda, M, 2010, Membuat Aplikasi Database Dengan Java, MySql dan NetBeans, Jakarta, Elex Media Komputindo. 